increasing the probability of unintended pregnancy and making recourse to abortion more likely.

But the harmful effects of Trump's order are likely be even greater. NGOs in low-income settings often provide integrated health services; for instance, they offer patients contraceptive care, HIV prevention or treatment, maternal health screenings, immunisations, and information on safe abortion care all under one roof. By expanding the gag rule to the full scope of US global health aid, hundreds more national and local NGOs will be forced to choose between drastic funding cuts (if they decline to sign the gag rule) or denying their patients the information and services that are their right (if they sign, and can no longer provide or discuss abortion). Millions of women living in low-resource settings may now be unable to obtain the care they need, when they need it.

The unprecedented scope of the Trump global gag rule validates the fears of many observers: reproductive health and rights worldwide will face a sustained attack in the next 4 years of the Trump Administration. This assault will almost certainly include defunding the United Nations Population Fund (UNFPA), as well as potentially drastic cuts to US overseas family planning aid. It will be mirrored domestically by efforts to restrict abortion access-for instance, by banning all private and public insurance coverage of abortion or prohibiting the most commonly used method for second-trimester procedures-and to shred the nation's family planning safety net, including by defunding Planned Parenthood. ${ }^{10,11}$

It is becoming clearer with each Trump executive order that not only reproductive health but also global health programmes and overall foreign assistance supported by the US Government are in grave jeopardy, as indicated by President Trump's repeated promises to "put America first". The social conservatives driving this agenda-who now control the US Presidency and both
Houses of Congress-are showing complete disregard for the millions of women, men, and children who will suffer the consequences, intended or not, of these regressive policies.

\section{Ann M Starrs}

Guttmacher Institute, New York, NY 10038, USA

astarrs@guttmacher.org

I am President and CEO of the Guttmacher Institute, a research and policy organisation committed to advancing sexual and reproductive health and rights in the USA and globally.

1 The White House. Presidential Memorandum Regarding the Mexico City Policy. Jan 23, 2017. https://www.whitehouse.gov/the-pressoffice/2017/01/23/presidential-memorandum-regarding-mexico-citypolicy (accessed Jan 30, 2017)

2 Barot S, Cohen SA. The global gag rule and fights over funding UNFPA: the issues that won't go away. New York: Guttmacher Institute, 2015. https://www.guttmacher.org/gpr/2015/06/global-gag-rule-and-fightsover-funding-unfpa-issues-wont-go-away (accessed Jan 30, 2017).

3 USAID. USAID'S family planning guiding principles and U.S. legislative and policy requirements. 2017. https://www.usaid.gov/what-we-do/globalhealth/family-planning/usaids-family-planning-guiding-principles-and-us (accessed Jan 30, 2017)

4 Kaiser Family Foundation. US funding for international family planning and reproductive health. April 25, 2016. http://kff.org/global-health-policy/ issue-brief/u-s-funding-for-international-family-planning-reproductivehealth/view/footnotes/ (accessed Jan 30, 2017).

5 PAI. Trump's global gag rule dramatically expands harmful health impacts Jan 25, 2017. http://pai.org/newsletters/stroke-pen-trumps-global-gag-ruledramatically-expands-harmful-health-impacts/ (accessed Jan 30, 2017)

6 Kaiser Family Foundation. The US Government and global health June 29, 2016. http://kff.org/global-health-policy/fact-sheet/the-u-sgovernment-and-global-health/ (accessed Jan 30, 2017).

7 Kaiser Family Foundation. The US Government engagement in globa health: a primer. Jan 27, 2017. http://kff.org/global-health-policy/report/ the-u-s-government-engagement-in-global-health-a-primer/ (accessed Jan 30, 2017).

8 Bendavid E, Avila P, Miller G. United States aid policy and induced abortion in sub-Saharan Africa. Bull World Health Organ 2011; 89: 873-80C.

9 Jones KM. Contraceptive supply and fertility outcomes: evidence from Ghana. Economic Development Cultural Change 2015; 64: 31-69.

10 Hasstedt K. Why we cannot afford to undercut the Title X national family planning program. Guttmacher Institute, Jan 30, 2017. https://www. guttmacher.org/gpr/2017/01/why-we-cannot-afford-undercut-title-xnational-family-planning-program (accessed Jan 30, 2017).

11 Hasstedt K. Understanding Planned Parenthood's critical role in the nation's family planning safety net. Guttmacher Institute, Jan 12, 2017. https://www. guttmacher.org/gpr/2017/01/understanding-planned-parenthoodscritical-role-nations-family-planning-safety-net (accessed Jan 30, 2017).

\title{
Calling for action on violence against women: is anyone listening?
}

In 2014, we issued a call to action in The Lancet to address violence against women. ${ }^{1}$ Has there been progress? Around the world, an inexcusable number of women suffer violence; latest estimates show that one in three women experience physical violence, sexual violence, or both by a partner and/or sexual violence by a nonpartner in their lifetime. ${ }^{2}$ Although persistent and new challenges to addressing violence against women remain, there have been important improvements in global policy action against violence. "The elimination of all forms of 
violence against women" is a target of the Sustainable Development Goal 5, to increase women's empowerment and gender equality. ${ }^{3}$ This global ambition recognises that eliminating violence against women is fundamental to sustainable human development and health for all. The images of millions of women, men, and children participating in the Women's Marches calling for women's rights, equality, and inclusion on Jan 21, 2017, are testimony that gender equality and women's rights are unifying issues of concern-and persistent worry-around the world.

The public health implications of violence against women and the importance of the health sector's role have also gained policy-level traction. At the 2016 World Health Assembly, a Global Plan of Action was approved to strengthen the health system's response to interpersonal violence. ${ }^{4}$ This plan laid out concrete actions for states, WHO, and other key actors, including building the skills of health-care providers so they can respond effectively to women who experience violence, and strengthening the capacity and linkages between services, including for mental health care. In low-income and middle-income countries, such services are extremely limited. WHO has also developed guidelines and tools on the healthcare response to intimate partner violence and sexual violence, ${ }^{5,6}$ and has supported countries like Afghanistan, Cambodia, Namibia, and Uganda, which are investing in training for health-care providers to support them to provide sensitive and effective care, support, and referrals for women who experience violence. Much more needs to be done to ensure that knowledge about how to address and prevent violence against women is systematically included in undergraduate medical, nursing, midwifery, and public health education, and in in-service training.

Importantly, the 2014 Lancet call to action and the WHO Global Plan of Action highlighted prevention, since such investments hold the greatest promise for reducing violence on a large scale. Encouragingly, prevention now features more explicitly in some national plans and there is a growing evidence base on effective prevention strategies, such as parenting programmes to reduce child maltreatment and neglect; combined economic and social empowerment programmes for women; and community level programmes for changing social norms and supporting equal, non-violent relationships.' There is also more dedicated funding for research to improve future interventions. For example, we expect the results of over 20 studies and evaluations supported by UK Aidfunded What Works to Prevent Violence Against Women and Girls initiative ${ }^{8}$ to be released at the end of 2018 which will provide evidence on effective interventions. Continued investment in research and better evidence on how to scale up effective models of prevention are key. Countries must also maintain support for necessary, often life-saving, services for survivors of violence, including health care, shelter, legal aid, and financial support programmes. These services are crucial to mitigate the impact of violence, support women's recovery, and break the cycle of violence, ${ }^{9}$ but countries are often challenged to ensure adequate coverage and meet women's needs.

Civil society continues to be the major voice in demanding women's right to live free of violence. For example, the GBV Prevention Network led by Raising Voices in Uganda used the Lancet call to action to work with other civil society groups across eastern and southern Africa. Concrete gains included a new Gender-Based Violence (GBV) Directorate within the Uganda police force and new mobile courts in Malawi that travel to remote villages so survivors can access justice (Michau L, Raising Voices \& GBV Prevention Network, Uganda, personal communication). Yet in some countries, advocates' abilities to promote change and hold governments to account are severely constrained or under threat.

In addition to focusing on the predominant intimate partner violence, action is needed on all forms of violence against women and girls, including sexual violence by strangers or acquaintances, sexual harassment, child sexual abuse, and trafficking, including that suffered by refugee women and girls fleeing war or in conflict settings. ${ }^{10-12}$ The landscape for preventing violence is changing alongside unprecedented levels of global mobility, including that prompted by conflict. Better evidence is needed on how to address migrant and displaced women's risks of gender-based abuses, and create greater avenues for education, equality, and economic empowerment. ${ }^{13}$

The growing attention to previously less-recognised forms of violence is welcome and overdue. At the same time, it is important to guard against swings in attention and funding, which may create fragmentation or unwarranted hierarchies of priorities. A coordinated prevention agenda is needed to tackle shared risk factors, and build protective mechanisms, such as genderequitable legislative reforms and women's and girls'

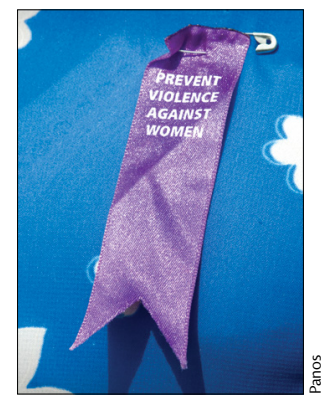

For GBV Prevention Network see http://preventgbvafrica.org/ 
equal participation in educational, social, political, and economic spheres. ${ }^{14} \mathrm{~A}$ joined-up response across relevant sectors will contribute to addressing multiple forms of violence against women and some of the interlinkages between violence against children and women.

Stopping generational cycles of violence requires recognition of the links between violence against women and violence against children. Evidence shows that children who witness their mothers being abused by their partners, or who are abused themselves, are more likely to develop mental health problems and be in violent relationships in later life, although this is not inevitable. ${ }^{15}$ Coordination between programmes directed at women and those focused on children is therefore important, so that services for women experiencing partner violence also provide safety and support to children in the same household; and interventions that seek to address child maltreatment give appropriate support to women who may be experiencing violence in the same household. ${ }^{16}$

At this moment in history, women's rights and the progress that has been made to improve the status of women are at serious risk of being hindered or even reversed. This includes threats of major cuts in funding to keep women safe in the USA ${ }^{17}$ and elsewhere, proposed legislative changes to decriminalise domestic violence in Russia, ${ }_{18}^{18}$ and the normalisation of sexual abuse and misogynist attitudes in some parts of the media, internet, and politics. Sustained engagement and commitment by governments, donors, advocates, and the public, as well as support for dedicated groups, is needed to continue to promote women's rights and safety. In a "post-truth" world, increased action is needed, backed by women, men, and especially young people across the political spectrum, if we wish to turn our call for a world without violence into a reality for all women, their families, and for their daughters.

*Claudia García-Moreno, Cathy Zimmerman, Charlotte Watts Department of Reproductive Health and Research, World Health Organization, 1211 Geneva 27, Switzerland (CG-M); Gender, Violence and Health Centre, London School of Hygiene \& Tropical Medicine, London, UK (CZ, CW); and Department for International Development, London, UK (CW) garciamorenoc@who.int
We declare no competing interests. The views in this publication are those of the authors. They do not necessarily reflect the policy or views of their organisations.

(c) 2017. World Health Organization. Published by Elsevier Ltd/Inc/BV. All rights reserved.

1 García-Moreno C, Zimmerman C, Morris-Gehring A, et al. Addressing violence against women: a call to action. Lancet 2015; 385: 1685-95.

2 Devries KM, Mak JY, García-Moreno C, et al. Global health. The global prevalence of intimate partner violence against women. Science 2013 340: 1527-28.

3 UN. Sustainable Development Goals. https://sustainabledevelopment un.org/sdgs (accessed Jan 25, 2017).

4 WHO. Global Plan of Action to strengthen the role of the health system within a national multisectoral response to address interpersonal violence, in particular against women and girls, and against children. Geneva: World Health Organization, 2016. http://apps.who.int/iris/bitstream/10665/ 252276/1/9789241511537-eng.pdf?ua=1 (accessed Jan 10, 2017)

5 WHO. Responding to intimate partner violence and sexual violence against women. WHO clinical and policy guidelines. Geneva: World Health Organization, 2013.

6 WHO. Health care for women subjected to intimate partner violence or sexual violence. A clinical handbook. Geneva: World Health Organization, 2014.

7 Ellsberg M, Arango D, Morton M, et al. Prevention of violence against women and girls: what does the evidence say? Lancet 2015; 385: 1555-66.

8 UK Department of International Development. What works in preventing violence against women and girls: review of the evidence from the programme. July 30, 2014. https://www.gov.uk/government/publications/ what-works-in-preventing-violence-against-women-and-girls-review-ofthe-evidence-from-the-programme (accessed Jan 11, 2017)

9 UK Department for International Development. What Works to Prevent Violence Against Women and Girls. Resources. 2017. http://www.whatworks. co.za/resources (accessed Jan 11, 2017).

10 Hossain M, Zimmerman C, Watts C. Preventing violence against women and girls in conflict. Lancet 2014; 383: 2021-22.

11 García-Moreno C. Responding to sexual violence in conflict. Lancet 2014 383: 2023-24.

12 McAlpine A, Hossain M, Zimmerman C. Sex trafficking and sexual exploitation in settings affected by armed conflicts in Africa, Asia and the Middle East: systematic review. BMC Int Health Hum Rights 2016; 16: 34.

13 International Labour Organization. Global estimate of forced labour: results and methodology. Geneva: International Labour Organization, 2012.

14 Heise L, Kostadam A. Cross-national and multi-level correlates of intimate partner violence: an analysis of data from population-based surveys. Lancet Glob Health 2015; 3: e332-40.

15 Millet LS, Kohl PL, Jonson-Reid M, Drake B, Petra M. Child maltreatment victimization and subsequent perpetration of young adult intimate partner violence: an exploration of mediating factors. Child Maltreat 2013; 18: 71-84.

16 Guedes A, Bott S, García-Moreno C, Colombini M. Bridging the gaps: a global review of intersections of violence against women and violence against children. Glob Health Action 2016; 9:31516.

17 Carlson M. How will President Trump handle violence against women in the US? The Hill. Jan 21, 2017. http://thehill.com/blogs/pundits-blog/theadministration/315427-how-will-president-trump-handle-violence-againstwomen (accessed Jan 24, 2017).

18 Seddon M. Russia's Parliament votes to decriminalize domestic violence. Financial Times. Jan 27, 2017. https://www.ft.com/content/e523d036e482-11e6-9645-c9357a75844a (accessed Jan 24, 2017) 